\title{
Development of an elbow-supporting device to assist standing-up motion
}

\author{
Haruna Eto ${ }^{*}$ and Hideichi Nakamoto
}

\begin{abstract}
In modern-day Japanese society, which is an aging society, an important issue is how to maintain the physical strength of elderly people. There are many studies to develop devices assisting with standing-up motion, because standing-up motion is a most important motion in daily life. Most of these studies suggested the devices to be placed in front of user's body or be used on the premise that a user balances between the right body and left body. And, they can assist standing-up motion effectively but their sizes are too large. One of the reasons why they cannot have been put into practical use seems to be that they are used with limiting a mounting location and interfere in the other motions of users. Therefore, we suggest an elbow-supporting device to assist standing-up motion, because we noticed that posture where an elbow is leaned on is generally comfortable and make user's upper body stable with supporting weight. And we developed a support device consisting of an armrest with two degrees of freedom. Using this device, a user can apply a load not to lower limbs but to the armrest with user's one elbow. This device on handrails is space-saving and doesn't interfere in the other motion of users. In this paper, we measured the surface electromyography (EMG) of three subjects' rectus under two conditions: not using any device and using the developed device. As the result, there is significant difference in the reduction in rectus femoris muscle activity when using the device. And we examined the suitable initial posture using this device and found that bending forward and tilting to an armrest are suitable initial posture. As a consequence, it was found that the suggested device can reduce the activity of lower limbs of a subject in that specific initial condition. Finally, in spite of a compact size of device, we showed a certain effect to assist standing-up motion in use an elbow-supporting device.
\end{abstract}

Keywords: Assistant device; Supporting device; Standing-up motion; Armrest; Human model

\section{Background}

\section{Study of assistance with standing-up motion}

In modern-day Japanese society, which has become an aging society, an important issue is the matter of how to maintain elderly persons' quality of life (QOL). The "standing-up motion" is one of the most important basic motions in daily life. Inability to perform the standingup motion disturbs many other actions. Therefore, there are many studies to assist standing-up motion [1-4]. These studies define the load applied to lower limbs of standing-up motion as the magnitude of torque of each joint in a human analysis model in a sagittal plane. Their aims are to minimize the torque. Moreover, rather than aiming to minimize torque, some studies instead focus

\footnotetext{
* Correspondence: haruna.eto@toshiba.co.jp

Toshiba R\&D Center, Komukai Toshiba-cho, Saiwai-ku, Kawasaki-shi, Kanagawa 212-8582, Japan
}

on control taking into account the physical strength shown by $[5,6]$. Most of these studies developed the devices to be in front of their body. And there only has been discussed that assist standing-up motion to support the load of body on both sides. However it was issue that these devices tend to be large and interfere in the other motions of users because of the placement. In addition, it is undesirable in terms of serving users with various solutions. We aim to develop a new device which a user can apply a part of his body weight to an armrest with his one elbow.

\section{Standing-up motion in elderly persons}

The results of standing-up motion very depending on the subject's age and physical condition, as well as the conditions of experiments, etc. [7,8]. An elderly person's physical abilities decrease more in the lower limbs than in the upper limbs [9]. Thus, the measurement of the 
actual activities of lower limbs is important for confirmation of the validity of the developed device supporting standing-up motion in elderly persons. Another feature in elderly people is that they cannot move quickly because their physical ability has declined unlike young people who tend to have confidence in their physical stability generally and are able to stand up quickly. However, a supporting system that moves too quickly for a person's body like a young person is unrealistic in terms of the stability of the person's posture and reliability in controlling the device. Thus, the device also needs to move slowly. In order words, the supporting device should be designed on the premise of moving slowly and should confirm the reduction of lower limb activity.

\section{The suggested device}

We suggest a new device supporting standing-up motion using the posture of leaning on one's elbow, which is familiar in our daily life. Y. Takahashi et al. [10] reported the development of a Handrail which can propel the center of gravity of Parkinson subjects forward to assist standing-up motion. The components of their system are similar to our suggested device, but they implemented inducement of the movement of standing-up motion, on the other hand, we tried to support a part of user's weight with his one elbow.

In this paper, we defined the surface electromyography (EMG) of rectus femoris muscle as the lower limb activity, because the muscle is protractor muscle at knee and concerns the standing-up motion essentially. We measured the EMG of three subjects' rectus femoris muscle under two different conditions: not using any device and using the developed device. We compared these with each other to confirm the validity of supporting standing-up motion. The two beneficial points are as follows:

- The ability of success in assisting the user's slow motion; and

- The stability of using few tools hardly restrains the user's body at all.

The device helps the user to be assisted successfully under some specific conditions including the user's initial posture. In this paper, we examined the posture in which the suggested supporting device could be successful.

\section{Methods}

\section{Outline of supporting devices}

Figure 1 shows overview of the developed device. The device consists of a base that moves horizontally along handrails, a vertical linear motion mechanism on the base and an armrest that on the motion mechanism. The armrest is moved horizontally by $350 \mathrm{~mm}$ and vertically by $350 \mathrm{~mm}$. We use urethane gel on a surface of armrest as the buffer material. A hand grip which users grip with both hands is placed at an edge of armrest. We use a 6-axis load/torque sensor (DYNPICK) below the armrest and a load sensor below the chair.

\section{Fundamental mechanism}

Here, we describe the fundamental mechanism how the elbow-supporting device reduces the load applied to lower limbs at standing-up motion.

Figure 2 shows force ratio to a subject weight at seat and foot using no device. This subject stood up carefully without acceleration. The force at foot abruptly increases as a subject left the seat. Especially the increase of the force is very large during early part of leaving. The most important point is that when the abrupt increase occurs, the angle at hip joint and knee joint are generally about 90 degree. - It is so unstable posture that the subject could drop backward. Therefore the abrupt of the force at foot increase causes the large load applied to lower limbs.

On the other hand, Figure 3 shows the force ratio to a subject weight at seat, foot and armrest using elbowsupporting device. The increase of force at foot is slow compared with Figure 2. It shows that the force at foot doesn't increase abruptly while the force at armrest occurs. The force at foot at the time after the "Stop" increased abruptly and it shows the motion of subject leaving an armrest. But it becomes a smaller load applied to lower limbs than leaving a seat without using any device, because at the same time her lower limbs were already stretched.

As a consequence, there is possibility that the suggested method is a valid method which reduces the load applied to lower limbs in standing-up motion.

\section{Experiment 1: confirmation of reduction in rectus femoris muscle activity}

Three subjects participated in the first experiment ( $\mathrm{S} 1$ to 3, 3 females, age: $30 \mathrm{~s}-40 \mathrm{~s}$, all without physical disability). We measured the deltoid, left femoris and right femoris respectively for subjects taking standing-up motion without using any device and standing-up motion using an elbow-supporting device.

In addition, we use the EMG (BIOPAC, MP150) to measure the activity of both rectus femoris muscle and deltoid with a sampling period of $1 \mathrm{kHz}$. Figure 4 shows the motion and specification of the elbow-supporting device and the place of the poles in EMG.

The center of chair is placed at $200 \mathrm{~mm}$ from the armrest in $\mathrm{X}$ direction. The path from the initial position to the end position of armrest is the linear. First, the user sits on a chair and leans on an elbow and also grips the hand grip with both hands to stabilize their body. Next, if the load sensor detects a specific vertical force value at the armrest, the device forces the user's body to move 


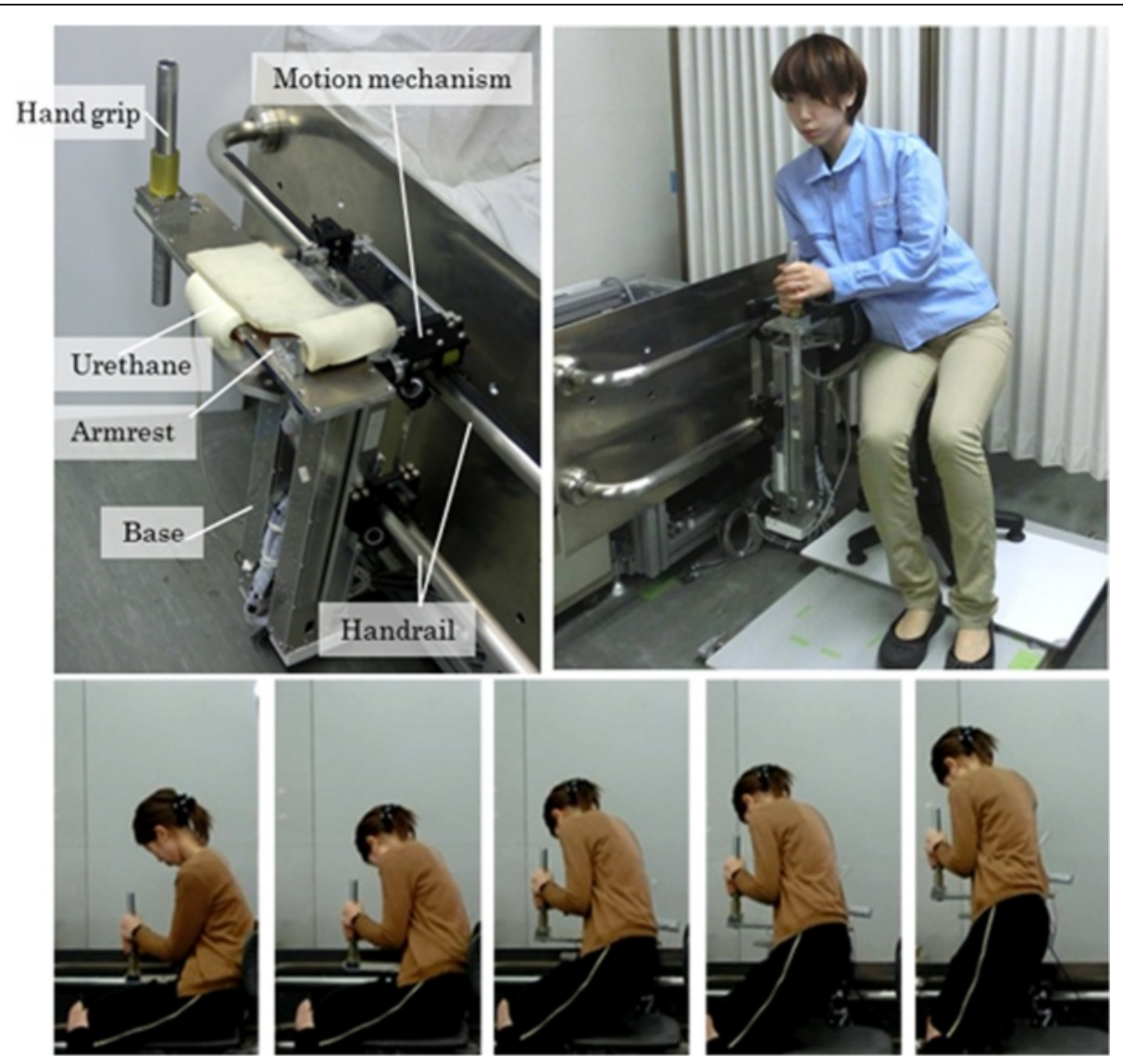

Figure 1 Overview of the developed device.

upward from the armrest, and stops the end position where the armrest reaches. We explain the method of these motions to these subjects, and after letting them practice a few times before the measurement. We measure data three times at least in each motion and subject.

\section{Experiment 2: examination of initial posture for stabilizing body}

In our suggested support method using the posture leaning against an elbow, the gravity load is not applied to the lower limbs and that load is instead applied to the elbow. Therefore, the success of supporting the standingup motion requires the user to sufficiently tilt their body towards the side of the armrest. Figure 5, 6, and 7 show the upper body model to estimate the degree of tilting body and the forces. Figure 5 shows the lengths of the model parts. Each value in Figure 5 uses an AIST/HQL database [11] as reference. Figure 6 shows the position and weight ratio of the center of gravity. Each value in Figure 6 uses the literature [12] as reference. We made the

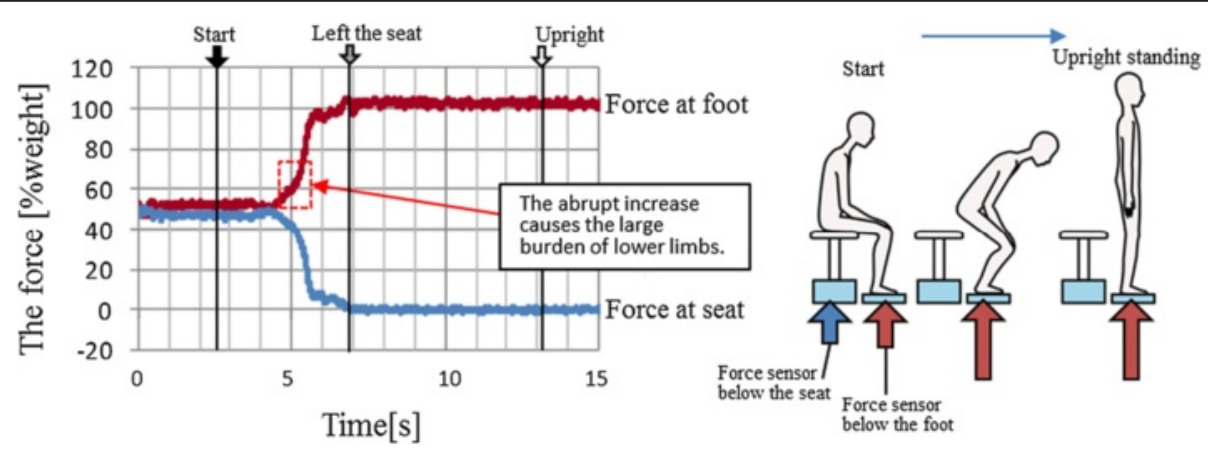

Figure 2 Force ratio to a subject weight at seat and foot using no device. 

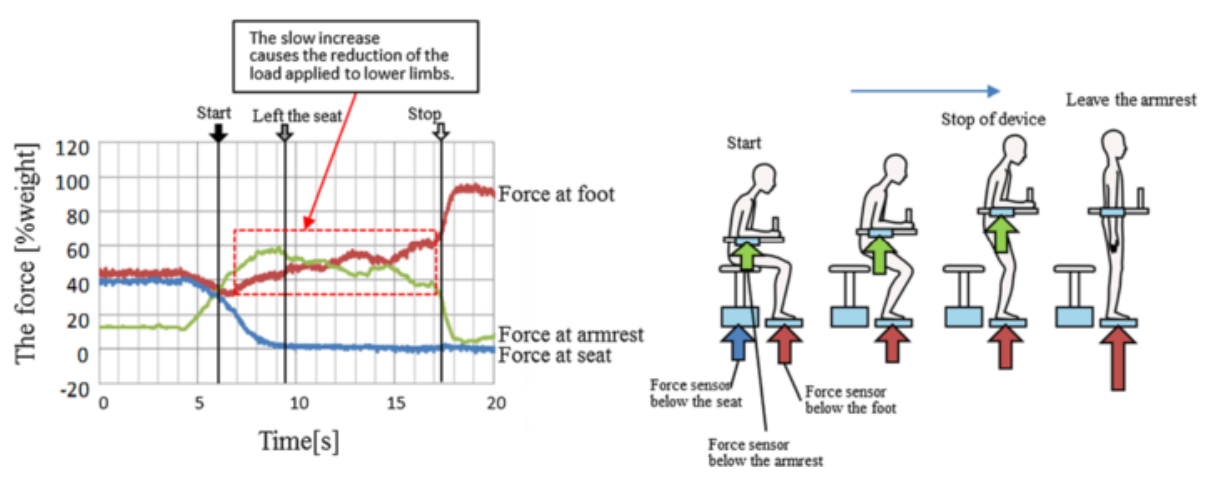

Figure 3 Force ratio to a subject weight at seat, foot and armrest using elbow-supporting device.

model of link in $x-y$ plane based on these data (Figure 7). We neglect forearms here because the weight of them is too lighter than other part of body. The assistant force $\mathrm{F}_{\text {assist }}$ upward from the armrest and the force $\mathrm{N}_{\text {seat }}$ upward from the seat equal the weight of model. Form(1) shows the torque $\mathrm{T}_{\mathrm{G}}$ generated by weight force $\mathrm{F}_{\mathrm{G}}$ and Form(2) shows the torque $T_{\text {assist }}$ generated by $F_{\text {assist }}$ when the body is tilted. If $\mathrm{T}_{\mathrm{G}}$ is equal to $\mathrm{T}_{\text {assist }}$, the upper body is stabilized. For example, the angle formed by the neck and shoulder $(\alpha)$ is the constant value based on the value of standing in the AIST/HQL database, as is the angle formed by the elbows. Also, we set the value of $\theta_{2}$ at zero for the sake of convenience. Thus the upper body is regarded as the rigid and Form(3) shows the relation between $\mathrm{T}_{\text {assist }}$ and $\theta_{1}$ when the upper body is stabilized.

We concern upper body in the model but lower body. Therefore, this model is only applied to the scene before

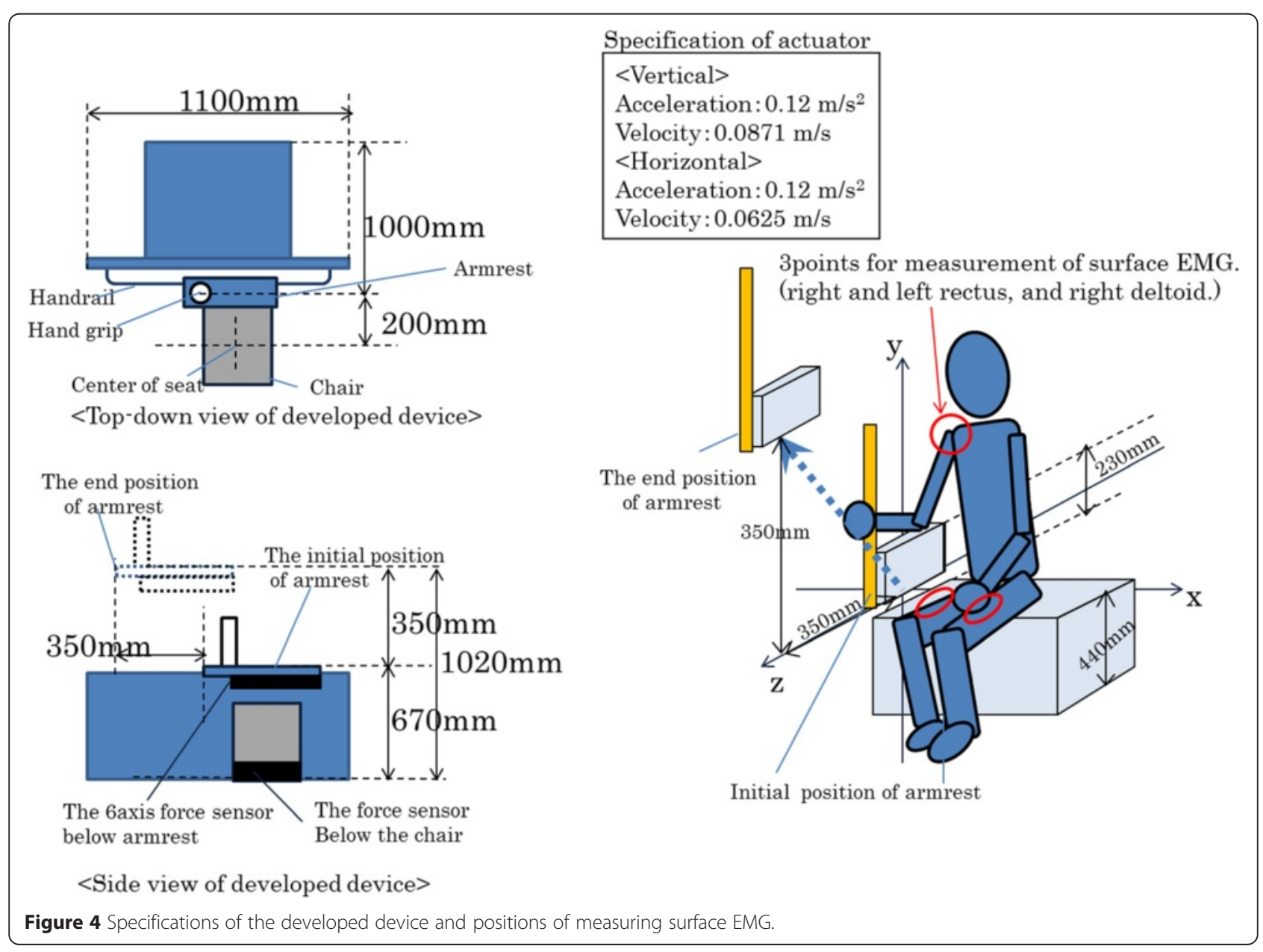




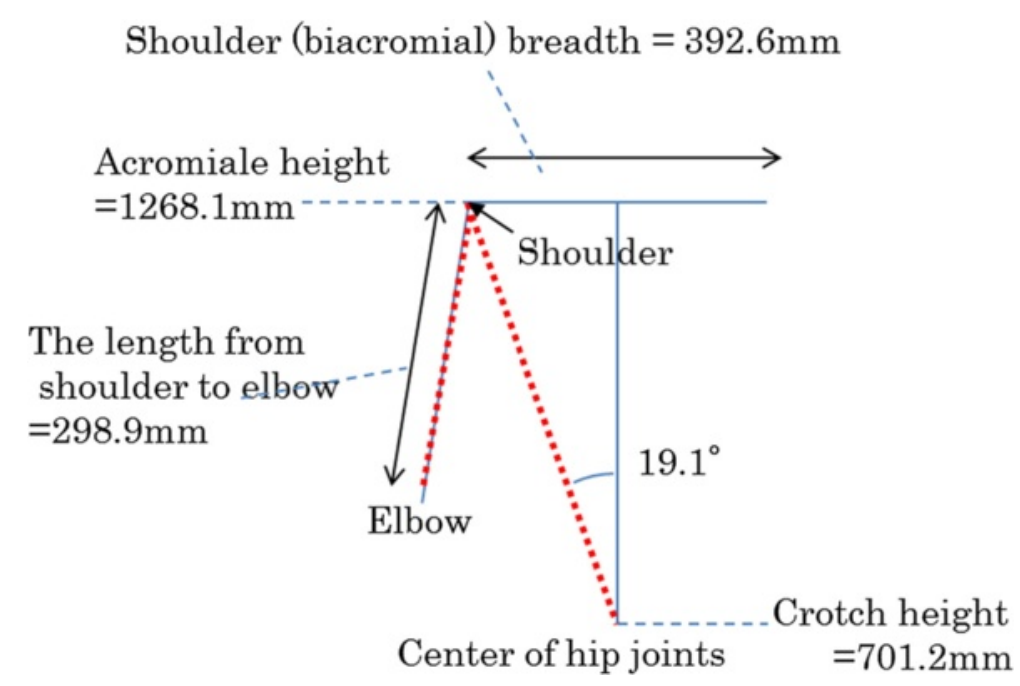

Figure $\mathbf{5}$ Lengths of upper body parts.

user left the seat. Because the model concerns the weight of lower limbs after the time at user left the seat.

$$
\begin{aligned}
T_{G}= & G(x) \cdot F_{G} \\
T_{\text {assist }}= & A(x) \cdot F_{\text {assist }} \\
\cos \theta_{1}= & A(x) \cdot F_{\text {assist }} / W \cdot\left(l R_{B} \cdot l_{B} \cdot R_{B}+\left(l R_{H N} \cdot l_{H N}+l_{B}\right) \cdot R_{H N}\right. \\
& \left.+2 \cdot\left(-l R_{U A} \cdot l_{U A}+\cos \alpha \cdot l_{S}+l_{B}\right) \cdot R_{U A}\right)
\end{aligned}
$$

Figure 8 shows the force on the elbow and the degree at which the body is tilted. Figure 8 show the model of using elbow-supporting device.
As shown in Figure 8(a), if the user's trunk is not tilting and receives the force from the device, rotation (CW) is generated at the center of the shoulder joint. This rotation makes the user unable to maintain this posture, and the user is thus unable to complete the standing-up motion. In such our experiment with participating subjects without physical disability, the subjects generate shoulder torque and keep a shoulder position where there is no rotation. Moreover, they stand up with their foot so as to avoid concentration of load on the shoulder. As a result, they receive no support from the device. However, as shown in Figure 8(b), this can likely be avoided if the user adequately tilts his/her body toward the elbow to begin with.

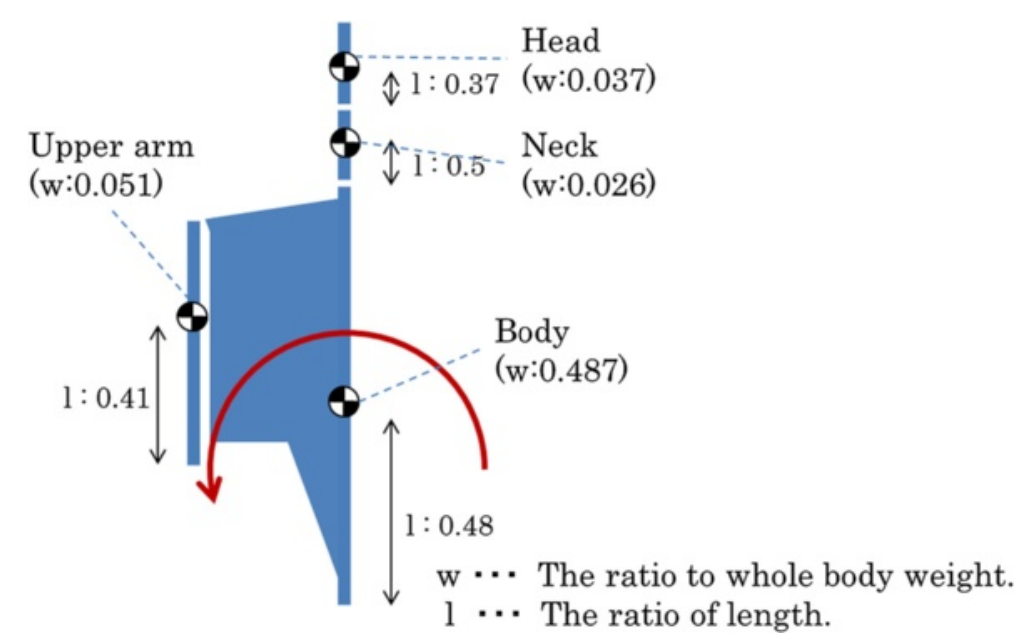

Figure 6 Position and weight ratio of center of gravity in right half upper body. 


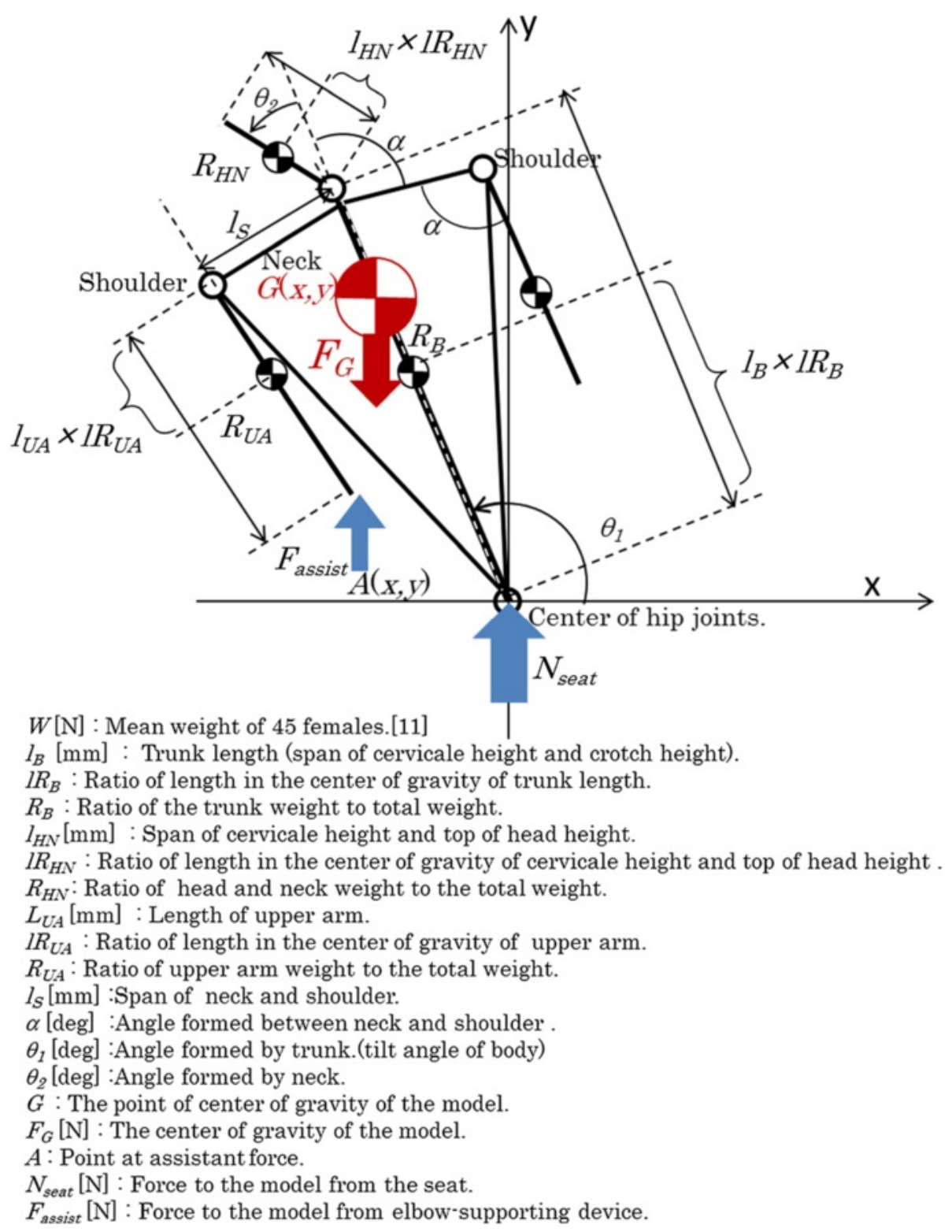

Figure $\mathbf{7}$ Upper body model.

If the user places a right elbow close enough to the trunk and tilts the upper body towards the elbow, load will not be concentrated on the right shoulder. Then, the upper body rotates (CCW) by the weight of each body part as the center of hip joints - actually there is not a joint at center of hip, but we assumed that there a joint at there for convenience. Thus, one's own weight and the force from the device are balanced with each other. In this case, the force from the device is generated adequately to make the user keep his/her posture, and works as the stabilizing force of the user's posture.

Based on the above, the second experiment aims to confirm that our suggested support method maintains the initial posture by changing the upper body posture where elbow assistance is started in one subject (S4, female, age: 20s).

Figure 9 shows each condition of the experiment. The subject makes a posture combining bending forward, bending backward, tilting to the right and tilting to the left in advance.

Table 1 shows the combinations A to D. Under these conditions, S4 makes a standing-up motion three times.

We directed S4 to place the same foot positions and the same seat position. Nevertheless, she felt that it was not supporting well, and we directed S4 to perform a standingup motion without stopping until the device stops. 


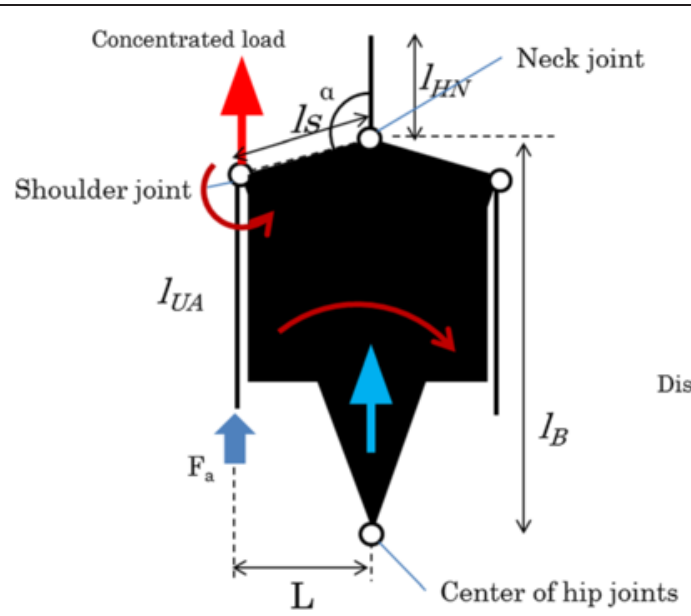

(a)Non-tilting boby

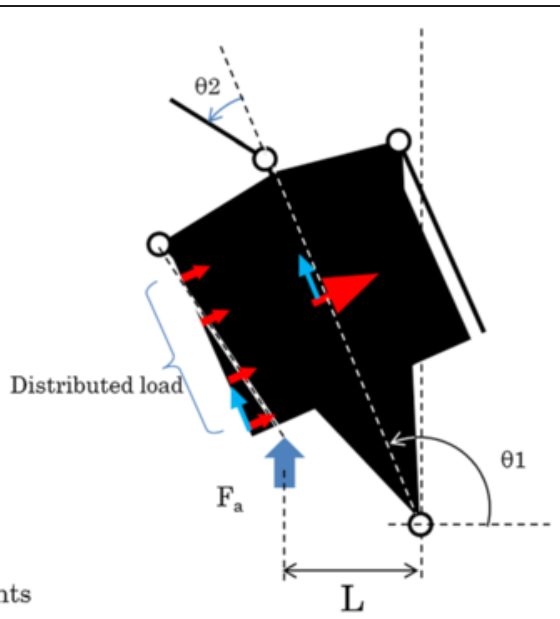

(b)Tilting body

Figure 8 Force to elbow and degree of tilting body.
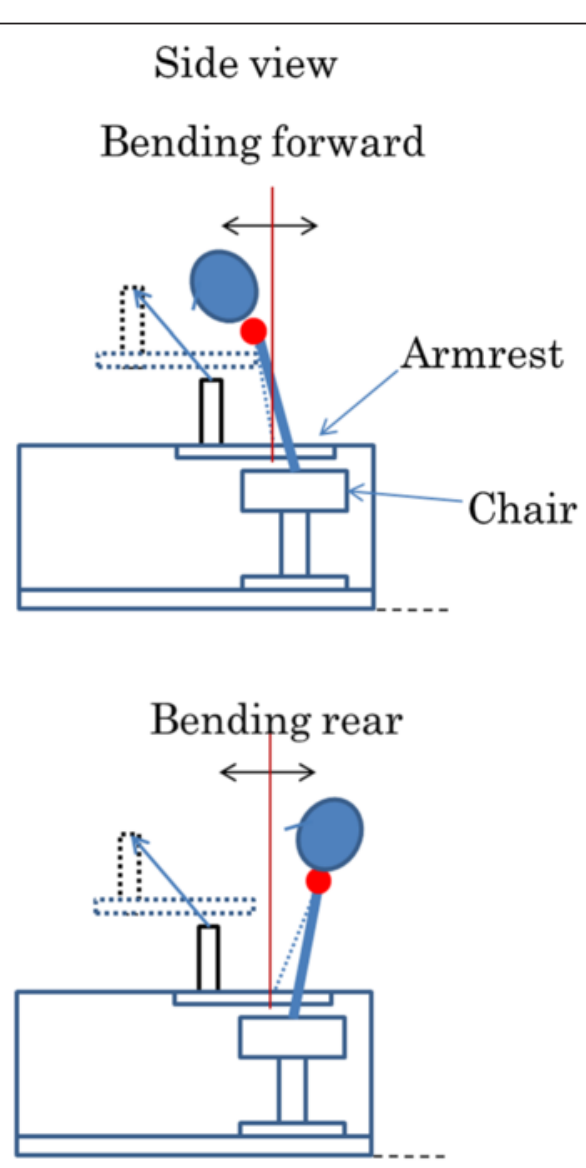

Figure 9 Initial postures in the experiment 2.

\section{Front view}

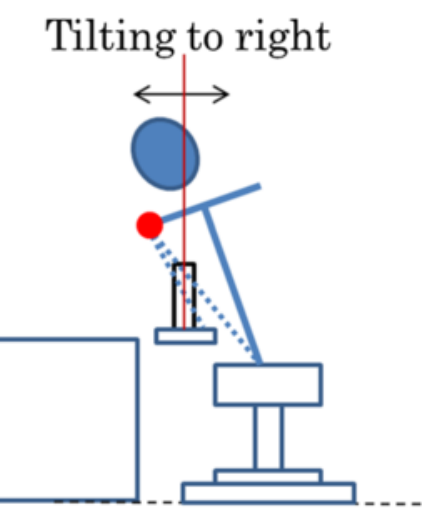

Tilting to left

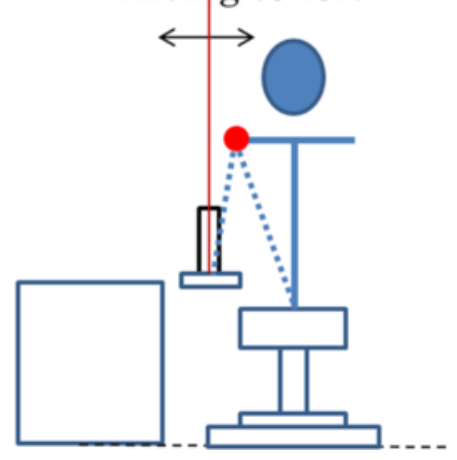


Table 1 Conditions and initial posture

\begin{tabular}{lll}
\hline Condition & Side view & Front view \\
\hline A & Bending forward & Tilting to right \\
B & Bending forward & Tilting to left \\
C & Bending rear & Tilting to right \\
D & Bending rear & Tilting to left \\
E & Normal standing-up motion takes $10[s]$ using no device \\
\hline
\end{tabular}

\section{Results}

\section{Results of experiment 1}

All EMG data are calculated root-mean-square (RMS) with $500 \mathrm{~ms}$ section. Figure 10 shows one of the EMG at slow standing-up motion using no device, Figure 11 shows one of the EMG at standing-up motion using an elbow-supporting device. Also, Figure 11 shows the ratio of vertical force to subject's weight put on the armrest and the seat, and the height of armrest. In that Figure, four times are shown: the first time when the motion of the device started (T1), the second time when a subject left the seat (T2), the third time when an armrest height equals the lliocristale height of a subject where the subject was upright standing (T3) and the fourth time when the motion of the device stopped (T4).

In Figure 10, the activities of both rectus femoris muscles increase during early part of motion and decline at the latter half. In contrast, in Figure 11 these activities are low. The activity of deltoid increases in the middle of motion and has a peak at about $10[\mathrm{~s}]$. In this experiment 1 , this activity of deltoid increases when a subject opens upper arm or grasps something strongly. Actually, we observed that the subject stopped leaning against the armrest and started to leave the armrest with raising her elbow at the time about $10[\mathrm{~s}]$. Thus, the peak of the activity of deltoid shows those two motions of grasping a handgrip and opening upper arm in the latter half. In addition, according to the ratio of force on armrest, the armrest supports about 40[\%] of weight around the time T2 when the subject left seat and on the other hand, the ratio declines at the latter half of motion. We found that the subject has kept the posture of upper body which she leans against an armrest, because the armrest has received a load continuously until T3 when an armrest height equals the lliocristale height of a subject. It means that the armrest pushed the upper body upward and the lower limbs has stretched. Therefore, we regard the posture at the time T3 as closing to upright.

Figure 12 shows each force at seat and armrest in using device respectively for all subjects. The force on the seat is $40 \sim 60$ [\%] when the subjects seated at the first and shifts to the force on armrest when subjects lean against armrest. If the force on seat is zero, one elbow and legs support subject's body. Like as in Figure 11, we show the time T3 when an armrest height equals the lliocristale height of each subject. In all subjects, the armrest has received a load continuously until T3. Also, in Figure 12 the force on armrest declines after T3. Therefore, it is found that the load of body weight applied to the elbow until stretching knee.

Figure 13 shows the activity ratio of rectus femoris muscle to the mean activity when each subject stands up using no device. The activity in using devise decreases in all subjects. Then, each calculated p-value is under 0.01 . Thus, we found that there are statistically significant differences in the reduction in rectus femoris muscle activity when using the device.

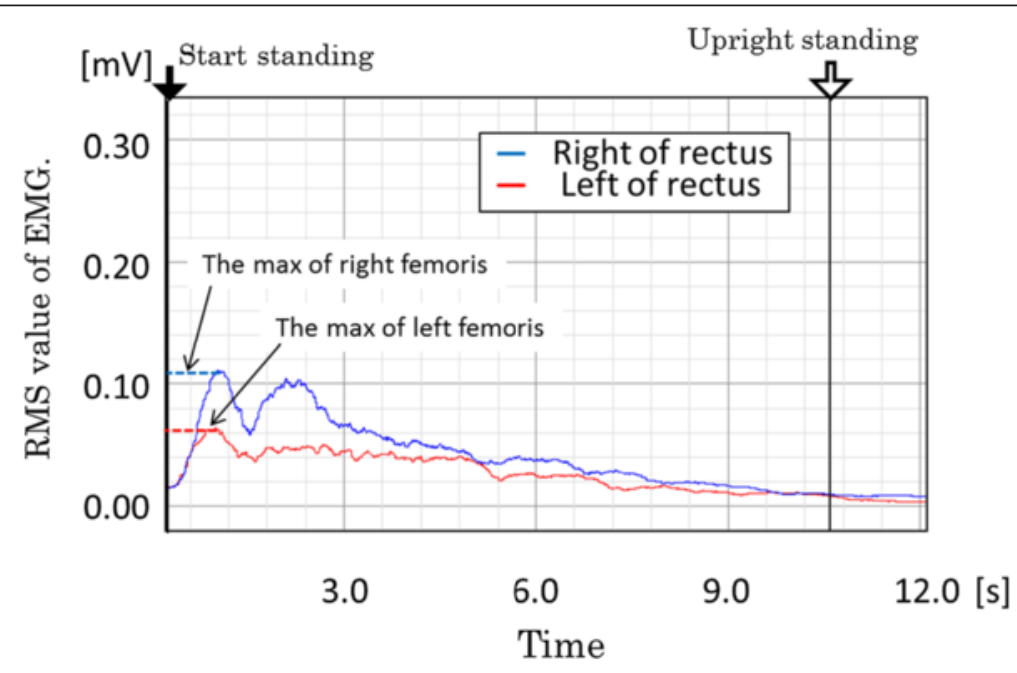

Figure 10 RMS value of EMG when S1 stood up using no device. 


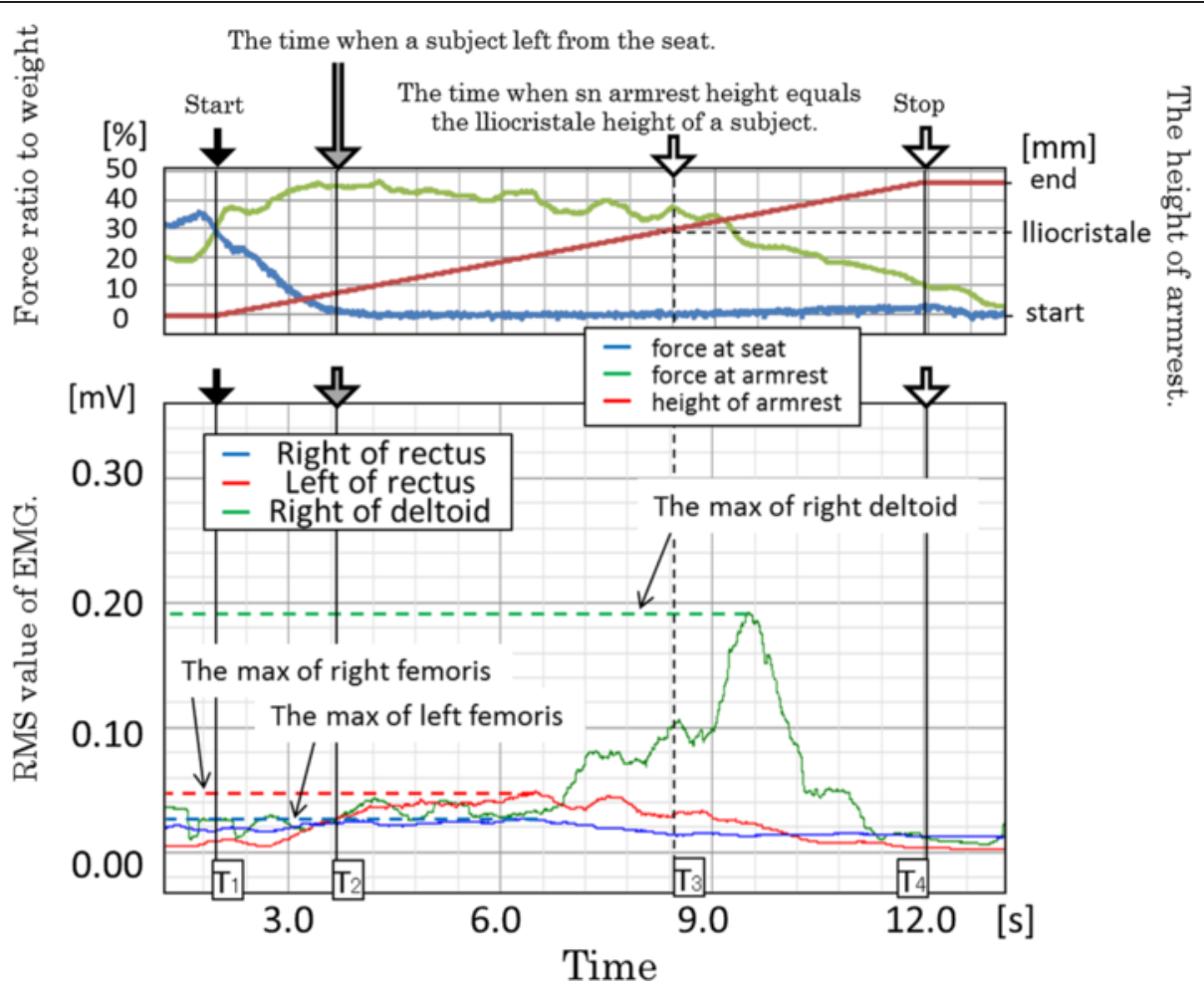

Figure 11 RMS value of EMG, vertical forces and armrest height when S1 used elbow-supporting device. Detailed: The ratio values of force based on a subject weight as $100[\%]$.

\section{Results of experiment 2}

Figure 14 shows the results of measuring EMG in conditions $\mathrm{A}$ to $\mathrm{D}$. The shoulder activity is low in conditions $\mathrm{A}$ and $\mathrm{C}$, but large in conditions $\mathrm{B}$ and D. Figure 15 show the activity ratio of rectus femoris muscle and deltoid of measurements under each condition. Also, deltoid activity is low in conditions $\mathrm{A}$ and $\mathrm{C}$ where the subject makes the posture of tilting to the right in advance, and it is high in conditions $B$ and $D$ where the subject does not make the posture of tilting to the right
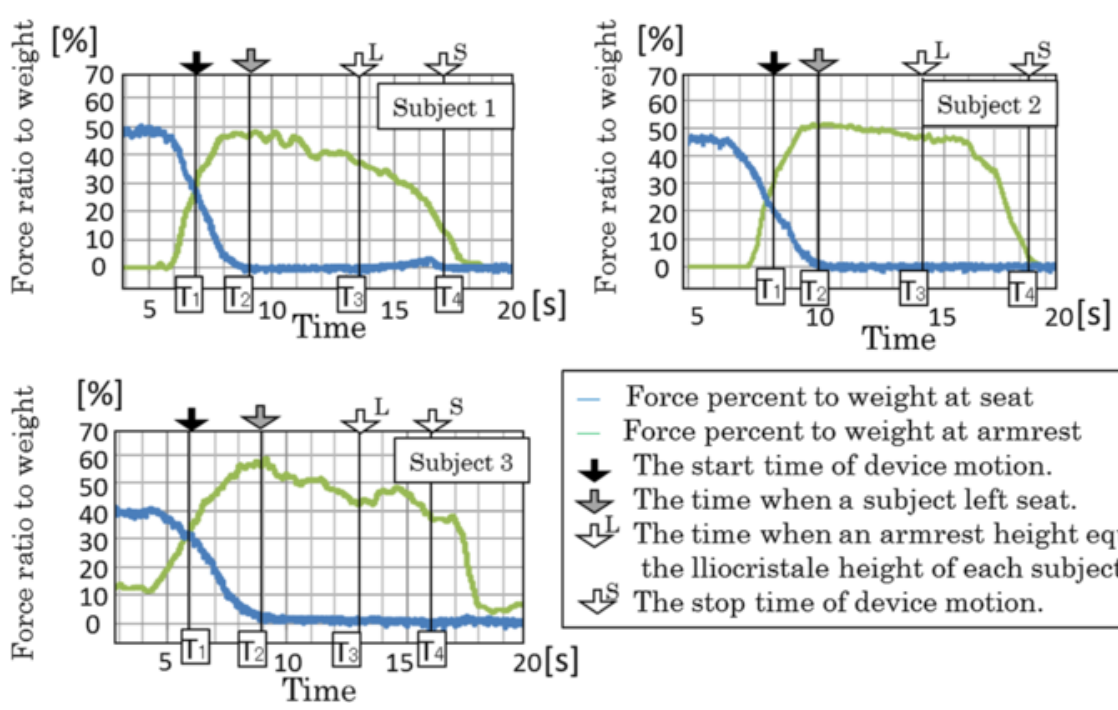

- Force percent to weight at seat

Force percent to weight at armrest

$\downarrow$ The start time of device motion.

』 The time when a subject left seat.

$\Omega$ The time when an armrest height equals

the lliocristale height of each subject.

nS The stop time of device motion.

Figure 12 Force ratio to each subject weight at seat and armrest. 


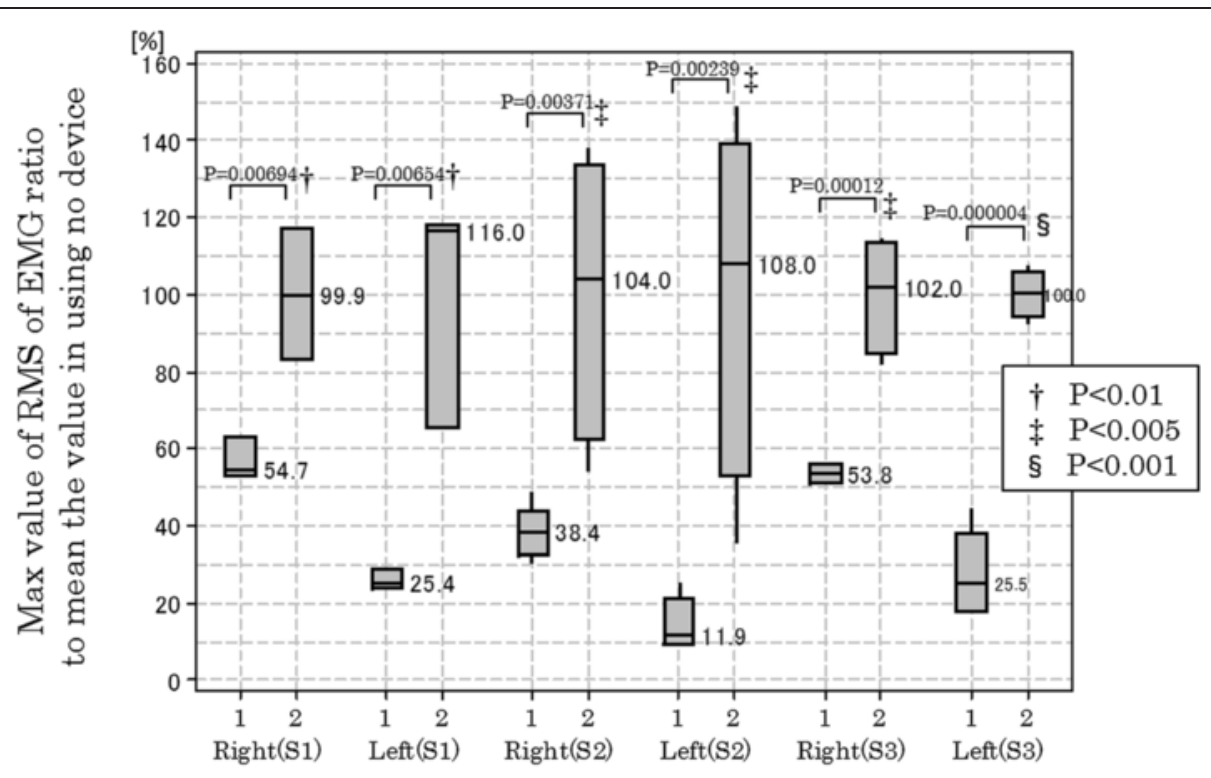

Subjects and conditions in experiment 1

(1: use elbow-supporting device, 2: using no device)

Figure 13 Activity ratio of both rectus femoris to mean in using no device in experiment 1.

in advance. The reason why the latter is higher than the former is that the subject raises her elbow a little and generates the torque at shoulder not to rotate because the armrest position is too far from the shoulder joint.

According to the results of conditions $\mathrm{B}$ and $\mathrm{D}$, deltoid activity is higher, and from the experiment we are sure that they stand up with their foot in order to avoid concentrating load towards the shoulder. Also, the posture of bending forward is usually an advantage in making the standing-up motion with buttocks getting up in advance. We observed this tendency from a comparison of conditions $\mathrm{AB}$ and $\mathrm{CD}$.

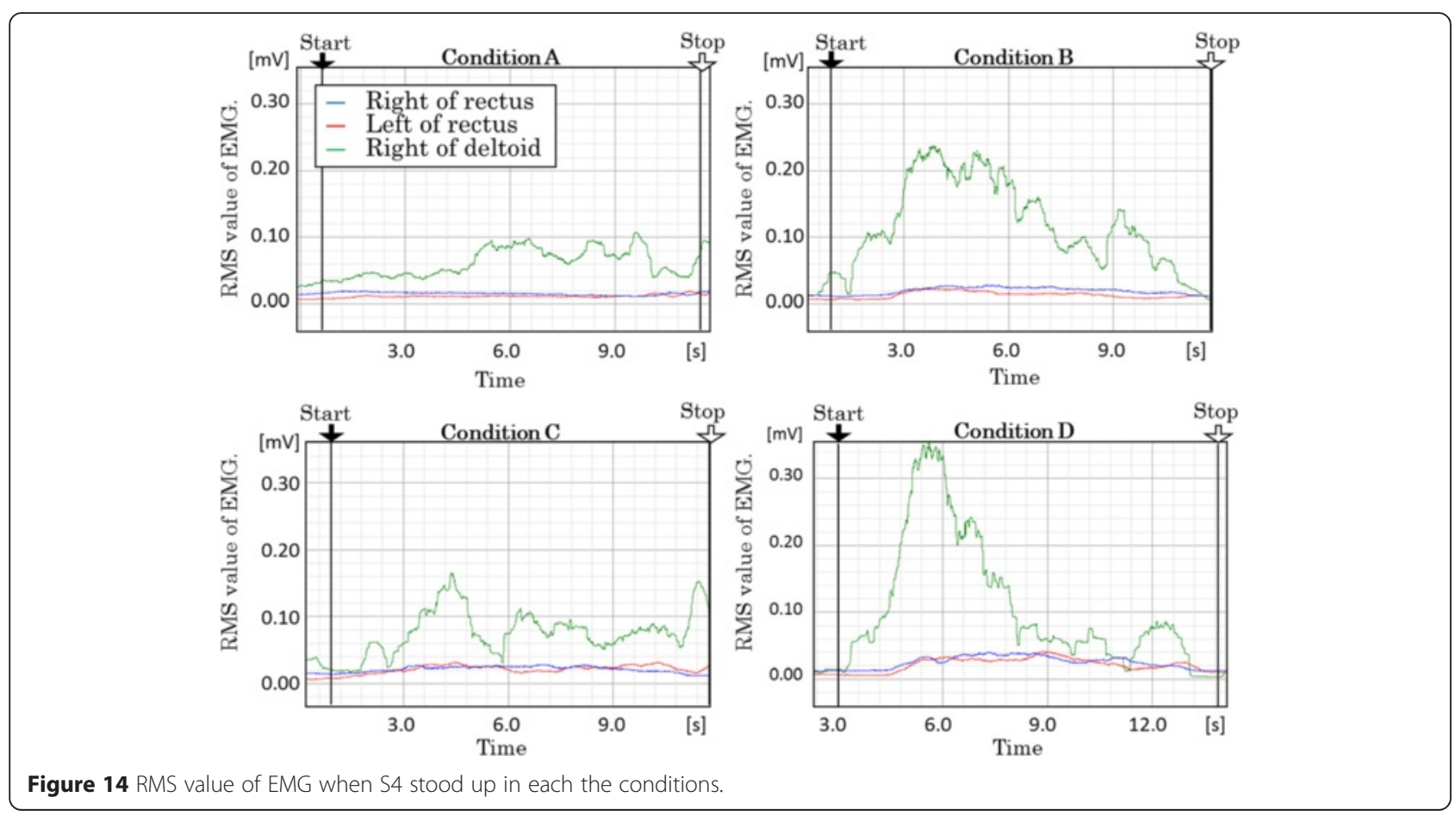




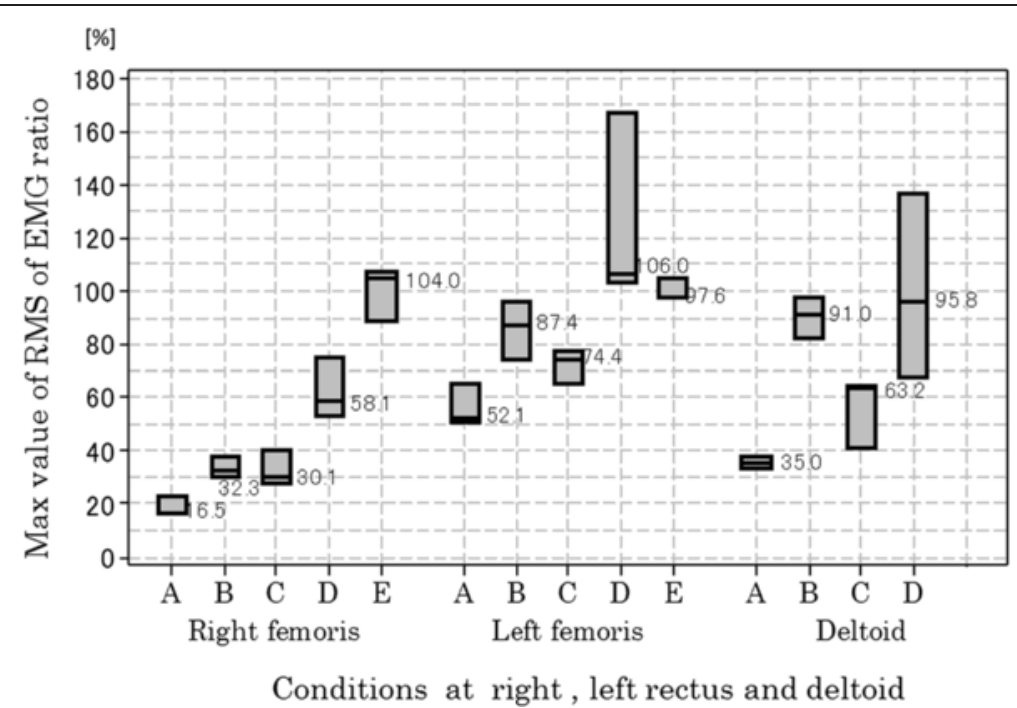

Figure 15 Activity ratio of rectus femoris and deltoid in experiment 2. Detailed: The ratio values of rectus femoris based on the maximum mean of RMS of EMG using no device as $100[\%]$. And the ratio values of deltoid based on the maximum mean of the maximum RMS of EMG in a motion each condition -it is condition D - as 100[\%].

In addition, in the result of conditions $C$, deltoid activity is high in advance. Because the subject didn't raise her elbow and her elbow didn't leave armrest, the activity was likely to be generated by grasping handgrip on the armrest. And in this condition $\mathrm{C}$, the trunk is right-angled to the path of device motion and the torque to rotate upper arm around shoulder joint in y-z plane. This is the reason why deltoid activity is high. Hence, we found that the optimum condition is A where all ratios are low.

\section{Discussion}

In Figures 11 and 12, we found that the armrest has received a load continuously until the time T3 in all subjects. But the force at armrest was different fluctuation subsequently each subject. Especially, S2 is below the average height. And the height of armrest at stopping device is higher than the height of elbow at upright standing. In this case, the armrest tends to push only her elbow upward forcibly, so it will become excessive load to shoulder joint. On the other hand, S1 and S3 close to the average, but we observed that S1 tends to stop leaning against the armrest and leave it gradually at the last and S3 tends to have leaned against the armrest continuously until the last. Therefore, the force at armrest of S1 in the latter half decline gradually and the force of S3 fluctuated. We need to verify the size of

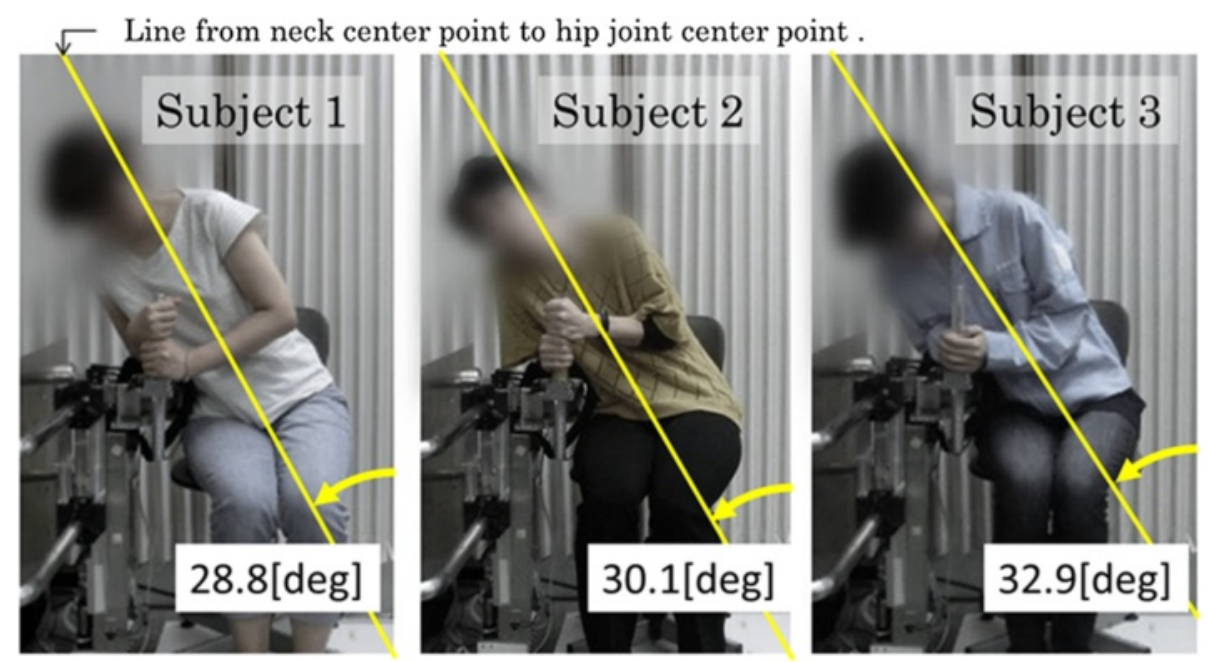

Figure 16 Actual initial postures of subjects in experiment 1. 
device for each individual and to design the movement well in the latter half.

And, the device helps the user to be assisted successfully under condition A. Then, we did not measure the angle of $\theta_{1}$ in experiment 1 , but we analyzed this from record image at the time $\mathrm{T} 2$ when a subject left seat, as the vertical line and the line from neck center point to center point of hip joints (Figure 16). The result is 28.8 [deg] in subject1, 30.1[deg] in subject2 and $32.9[\mathrm{deg}]$ in subject3, and all subjects prepared for a degree of about $30[\mathrm{deg}]$. According to Figure 12, the value of force are 48[\%], 50[\%] and 58[\%] when the photos are recorded. By the way, we substitute $A(x)(=200 \mathrm{~mm})$ for Form(2) and we substitute these degree for Form(3) and also calculate the force ratio. As a result, the experimental values approximately match the theoretical values (Figure 17). We clarified that the actual subject's posture in advance in experiment 1 were stabilizing upper body and it is about decided by the percent force at armrest to weight.

Now, Table 2 and Figure 18 shows the sitting length from the seat face to the elbow. And, according to hearings with subjects after the experiment 1 , although all subjects said that the suggested device helped their lower limbs, S2 said that she felt uncomfortable to her arms. In Table 2, the sitting length from the seat face to the elbow of S2 is the smallest. And, we found in Figure 16 that S2 looks up because the initial armrest position was too high for her. This condition is not optimum in experimental 2 . Therefore, the initial height of armrest is too high for S2 and it might have been already a load applied to her arm in the first.

Here, we examined the relationship between the degrees of tilting body of subjects according to Figure 16 and the measurement values of their upper arm lengths. But there is no correlation between them. Because there are cases when subjects make their postures (not only tilting in frontal plane but also) twisting their body toward the device.

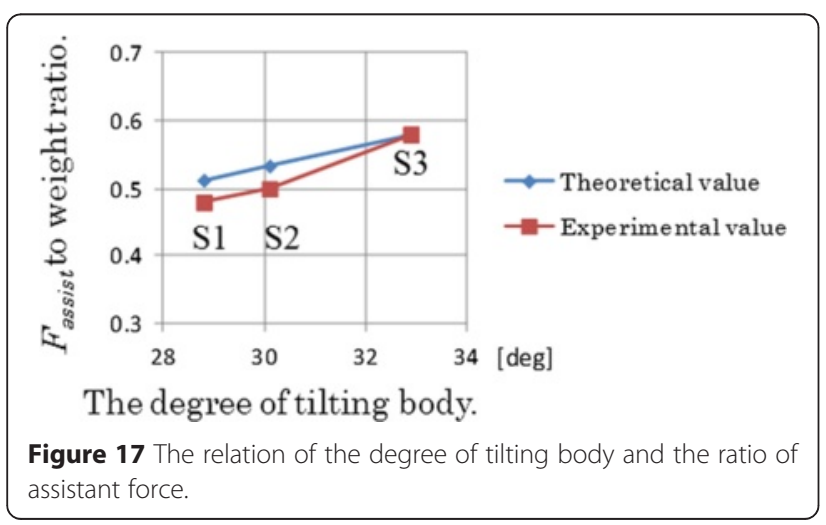

Table 2 Each sitting length from the seat face to the elbow [mm]

\begin{tabular}{llll}
\hline Subject $\mathbf{1}$ & Subject $\mathbf{2}$ & Subject $\mathbf{3}$ & The device \\
\hline 220 & 210 & 230 & $230^{*}$ \\
\hline *This is the length from the seat face to the armrest at initial position.
\end{tabular}

As the above, to enable an individual to make the initial posture in an optimum condition we need to design the initial height of the armrest.

\section{Conclusion}

In this paper, we focused on that some previous effective methods to assist standing-up motion cannot have been put into practical use because of their large sizes and developed a prototype of elbow-supporting device to assist standing-up motion for space-saving. We examined basically the device and measured EMG of three subjects' rectus under two different conditions: not using any device and using the developed device. As the result, there is statistically significant difference in the reduction in rectus femoris muscle activity when using the device. And we found that although the activity isn't reduced in some initial posture, the suitable initial posture is bending forward and tilting to an armrest. Moreover, we made an upper body model in frontal plane that shows the relationship between the degree of body tilt and the supporting force to the user from the developed device's armrest under the condition of upper body is stable. And we found the experimental values approximately match the theoretical values. Finally, it is likely to be a possibility of in use an elbow-supporting device to assist standing-up motion. However, it is not clearly that the suggested device might lead some bad conditions of body because of the mechanism different on right and left human body, or not. Thus, we expect not long usage of our device but temporary usage for people who feel

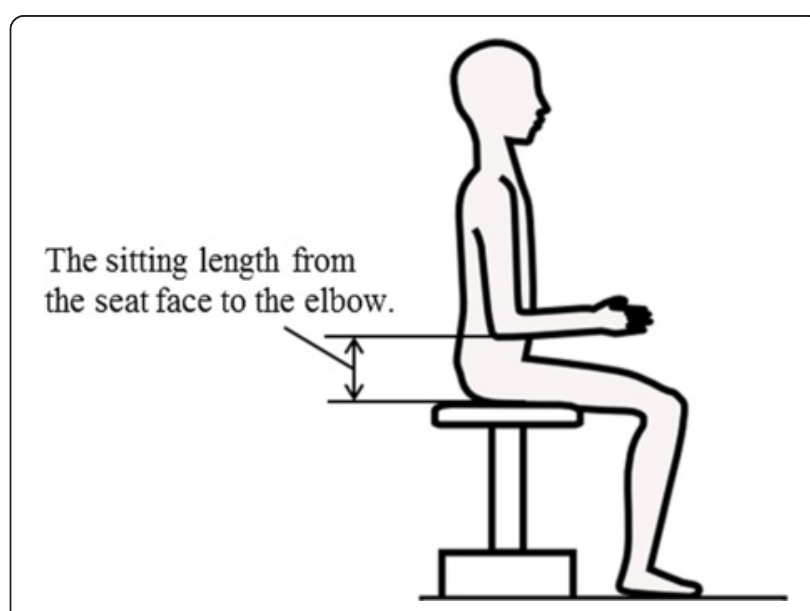

Figure 18 The sitting length from the seat face to the elbow. 
some difficulty in standing-up motion because they have an injury or some trauma. We showed in this paper that in spite of a very compact size of device, our suggested method seems to be effective method to assist standingup motion. In addition, all results in this paper are in subjects without physical disability. We need to continue further in-depth examination of the scope of users and the size of the device for individuals.

\section{Competing interests}

The other authors declare that they have no competing interests.

\section{Authors' contribution}

HE proposed an elbow-supporting device to assist standing-up motion, did the verification experiment of the effect of the device and drafted the manuscript.HN designed the device and helped to draft the manuscript. Both authors read and approved the final manuscript.

Received: 6 October 2014 Accepted: 20 April 2015

Published online: 02 May 2015

\section{References}

1. Hemami H, Vijay JC (1978) On a three-link model of the dynamics of standing up and sitting down. IEEE Trans Syst Man Cybem 8(2):115-120

2. Tomita M, Ogiso T, Nemoto Y, Fujie MG (2000) A study on the path of an upper-body support arm used for assisting standing-up and sitting-down motion. JSME Int J Series C 43(4):949-956

3. Matsuhira N, Fukushima T, Nukada H, Sunaoshi T (2012) Development of the supporting apparatus for standing up motion of the elderly person: Basic experiment of standing up motion. IEEE/SICE International Symposium on System Integration. pp 361-365

4. Takamura T, Sanada K (2004) A study on measurement of assist force of power-assisted chair. Yamanashi district conference 2004. pp 233-234, Japanese

5. Tsukahara A, Hasegawa Y, Sankai Y (2009) Standing-up motion support for paraplegic patient with Robot Suit HAL. Proceedings of the 2009 IEEE 11th International Conference on Rehabilitation Robotics. Kyoto. 211-217

6. Chugo D, Kawabata K, Kaetsu H, Asama H, Miyake N, Kosuge K (2006) Force Assistance System for Standing-up Motion.Proceedings of 2006 IEEE International Conference on Mechanics and Automation. Luoyang. pp.1103-1108

7. Wim GMJ, Hans BJB, Henk JS (2002) Determinants of the Sit-to-Stand Movement: A review. Phys Ther 82:866-879

8. Qi A, Ishikawa Y, Nakagawa J, Oka H, Yamakawa H, Yamashita A, Asama H (2013) Muscle Synergy Analysis of Human Standing-up Motion in Different Seat Heights and Speeds. IEEE SMC, 2013 IEEE International Conference on. pp 3579-3584

9. Nakatani T, Nadamoto M, Mimura K, Itoh M (2002) Validation of a 30-sec chair-stand test for evaluating lower extremity muscle strength in Japanese elderly adults. Japan J Phys Educ HIth Sprt Sci 47:451-461, Japanese

10. Takahashi Y, Nitta O, Okikawa S, Komeda T (2006) Development of a Power Assisted Handrail - Handrail Trajectory and Standing Up Motion. Lecture Notes Comp Sci 4061:935-942

11. Kouchi M, Mochimaru M (2003) 2003:AIST/HQL the human body database 2003.National Institute of Advanced Industrial Science and Technology. https://www.dh.aist.go.jp/database/fbodyDB/. Accesed 28 Sep 2014

12. Nakamura R, Saito H (1976) Fundamental Kinesiology 4th ed. Ishiyaku publishers, Tokyo

\section{Submit your manuscript to a SpringerOpen ${ }^{\odot}$ journal and benefit from:}

- Convenient online submission

Rigorous peer review

- Immediate publication on acceptance

- Open access: articles freely available online

- High visibility within the field

- Retaining the copyright to your article

Submit your next manuscript at $>$ springeropen.com 